\title{
Alterations in pubertal development in adolescents with leukemia in the surveillance phase
}

\author{
Héctor Eliud Arriaga-Cázares', Mara Alejandra Cázares-Bellazetin, Luz María Sánchez-Sánchez, \\ Ana Laura Bahena-García ${ }^{1}$ and Gerardo del Carmen Palacios-Saucedo ${ }^{2}$

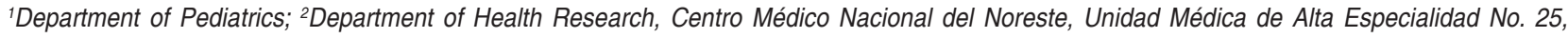 \\ Instituto Mexicano del Seguro Social, Monterrey, N.L., Mexico
}

\begin{abstract}
Objective: To evaluate which factors are associated with alterations in pubertal development in pediatric patients with leukemia in the surveillance phase. Methods: A case-control study was carried out, including patients aged 8-14 years with diagnosis of acute lymphoblastic leukemia under surveillance. Demographic data were collected, age at diagnosis, type of leukemia, risk of leukemia, duration and type of treatment received, time of surveillance phase; and pubertal development was assessed by Tanner stage, bone age, pelvic ultrasound for women, and LH levels. Fisher's exact test and Mann-Whitney U-test were used. Results: Twenty-five pediatric patients with a diagnosis of acute lymphoblastic leukemia between 8 and 14 years of age with a median of 8 were included, only 4 (16\%) presented pubertal alterations, 1 had pubertal delay and 3 advanced puberty. The history of radiotherapy was related to pubertal alterations $(p=0.03)$. Conclusions: The antecedent of having received radiotherapy as part of the treatment in patients with acute lymphoblastic leukemia is a risk factor for developing pubertal abnormalities.
\end{abstract}

KEY WORDS: Acute lymphoblastic leukemia. Alterations in pubertal development. Radiotherapy.

\section{Introduction}

The number of acute lymphoblastic leukemia survivor children has increased over the past few years, owing to an important improvement in therapeutics since the introduction of combination chemotherapy and preventive measures to avoid leukemic infiltration to the central nervous system, with a disease remission percentage reported of around $80 \%$. However, with these treatment advances and survival improvement, numerous health complications, not yet fully described, have been continuously observed ${ }^{1,2}$.

Endocrine alterations in patients with acute lymphoblastic leukemia can occur during the disease or secondarily to the treatment even several years later, and are dependent on the age at disease onset, treatment, gender and time elapsed since treatment conclusion.
Complications include gonadal dysfunction, infertility and pubertal development disorders ${ }^{3,4}$.

Prepubertal age at treatment initiation has reported not to protect from gonadal damage; on the contrary, children who received radiotherapy at an early age had some growth or pubertal development disorder, and no clinical, hormonal or echographic marker able to determine if there is gonadal insufficiency has been identified so far ${ }^{5,6}$.

The purpose of this study was to assess which factors are associated with pubertal development alterations in pediatric patients with leukemia on surveillance phase.

\section{Method}

A case-control, observational, longitudinal, ambispective, analytical study was carried out, where

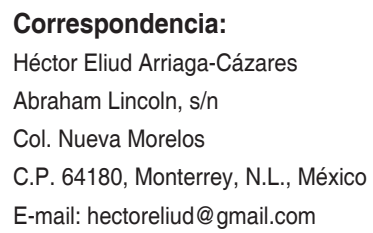

Date of reception: 4-12-2016

Date of acceptance: 11-01-2017

DOI://dx.doi.org/10.24875/GMM.M18000088
Gac Med Mex. 2017;153:821-824

Contents available at PubMed www.gacetamedicademexico.com 
patients aged from 7 to 14 years and 11 months, diagnosed with acute lymphoblastic leukemia on surveillance phase, under the care of No. 25 High Specialty Medical Unit (UMAE - Unidad Médica de Alta Especialidad) from January to August 2015, were included.

Demographic data, age at diagnosis, type of leukemia, risk of leukemia, received treatment duration and type, as well as time on surveillance phase were recorded. Pubertal development was assessed by Tanner stage determination, bone age, pelvic ultrasound for females and luteinizing hormone (LH) values of patients with acute lymphoblastic leukemia on surveillance phase attended to in our hospital (Table 1).

The chi-square test or Fisher's exact test were used for categorical variables, and Student's t-test and Mann-Whitney U-test were used for quantitative variables. Statistical significance was considered at a $p$-value $<0.05$, with the results being analyzed with the statistical program SPSS 15.0.

\section{Results}

Twenty-five pediatric patients diagnosed with acute lymphoblastic leukemia of between 8 and 14 years of age, with a median of 10 years (8-15) with normal puberty and 8 years (8-9 years) with altered puberty, on surveillance by UMAE No. 25 outpatient clinic and who accepted to participate in the study by granting their informed consent were included. Among them, $10(40 \%)$ were males and $15(60 \%)$ were females, with altered results predominating in the male gender with 3 patients $(75 \%)$, and $1(25 \%)$ of the female gender $(p=0.126)$; there was only one with delayed puberty (25\%).

All patients were tested for $\mathrm{LH}$, bone age and pelvic ultrasound in the case of the girls, and underwent a Tanner assessment and a somatometry at the office. For their study, the patients were divided according to whether they had normal or abnormal pubertal development. Four patients (16\%) had altered pubertal development, out of which three had precocious pubertal development and, one, delayed, whereas 21 (84\%) a normal pubertal development and in accordance to their age.

The age at acute lymphoblastic leukemia diagnosis had a median of 5 years (1-13 years) in patients with normal pubertal development, and of 6 years (2-7 years) $(p=0.716)$ in those with abnormal pubertal development. The male gender was predominant: $3(75 \%)$ with altered result and $1(25 \%)$ of the female gender $(p=0.126)$. Acute lymphoblastic leukemia was classified by risk: of the patients with normal puberty, 15 had usual risk $(60 \%)$, one had moderate risk $(4 \%)$ and 9 were at high risk (36\%); of the patients with abnormal puberty, two had usual risk $(50 \%)$, no one had moderate risk $(0 \%)$ and two were at high risk $(50 \%)(p=0.767)$.

As for the somatometry, weight had a median of $38 \mathrm{~kg}(23.5-75.7 \mathrm{~kg})$ in the patients with normal pubertal development and of $38 \mathrm{~kg}(22.5-47 \mathrm{~kg})$ $(p=0.593)$ in those with normal pubertal development. Height had a median of $1.4 \mathrm{~m}(1.2-1.7 \mathrm{~m})$ in the patients with normal pubertal development and of $1.3 \mathrm{~m}(1.2-1.5 \mathrm{~m})(p=0.334)$ in those with abnormal pubertal development.

As for radiotherapy history, among the patients with no pubertal alteration, two (50\%) had received radiotherapy, and among the patients who did have pubertal alteration, radiotherapy had also been applied to two $(50 \%)(p=0.03)$.

With regard to Tanner assessment in patients without pubertal alteration, five patients $(23.80 \%)$ were found to be at stage I, eight $(38.09 \%)$ were found to be at stage II, five $(23.80 \%)$ at stage III, two $(9.52 \%)$ at stage IV and one $(4.76 \%)$ at stage $\mathrm{V}$; of the patients who did exhibit pubertal alterations, two $(50 \%)$ were found to be at stage II, one (25\%) at stage III and one $(25 \%)$ at stage IV) $(p=0.747)$

As for gonadal relapse, it was only assessed in males, since testicles are one of the sanctuary organs that are taking into account for risk of disease, with $1 / 3$ pubertal alteration (33\%).

Two patients (50\%) had relapse to the central nervous system among those with pubertal alteration, as well as three (14\%) patients among those with normal pubertal development $(p=0.126)$.

Pelvic ultrasound in the girls yielded 10 abnormal $(26.6 \%)$ and 4 normal $(66.6 \%)$ results in patients with normal pubertal development, and one abnormal result (6.6\%) among the patients with abnormal pubertal development $(p=0.157)$.

Hormone results were as follows: follicle-stimulating hormone with a median of $3.8 \mathrm{mg} / \mathrm{dL}(0.8-20.2 \mathrm{mg} / \mathrm{dL})$ in patients with normal pubertal development and of $2.06 \mathrm{mg} / \mathrm{dL}(0.26-6.91 \mathrm{mg} / \mathrm{dL})(p=0.440)$ in those patients with abnormal pubertal development; LH had a median of $1.49 \mathrm{mg} / \mathrm{dL}(0.06-8.16 \mathrm{mg} / \mathrm{dL}$ in patients with normal pubertal development and of $0.88 \mathrm{mg} / \mathrm{dL}$ $(0.2-2.99 \mathrm{mg} / \mathrm{dL})(p=0.796)$ in those patients with abnormal pubertal development; and estradiol had a median of $4,97 \mathrm{mg} / \mathrm{dL}(0-119 \mathrm{mg} / \mathrm{dL})$ in patients with 
Table 1. Clinical and hematological characteristics, gonadotrophic hormones and pelvic ultrasound in 25 pediatric patients with acute lymphoblastic leukemia on surveillance at No. 25 UMAE

\begin{tabular}{|c|c|c|c|}
\hline & \multicolumn{2}{|c|}{ Pubertal development } & \multirow[t]{2}{*}{ p } \\
\hline & $\begin{array}{l}\text { Normal } \\
(n=21)\end{array}$ & $\begin{array}{c}\text { Abnormal } \\
(n=4)\end{array}$ & \\
\hline \multicolumn{4}{|l|}{ Gender } \\
\hline Male & 7 & 3 & \multirow[t]{2}{*}{0.158} \\
\hline Female & 14 & 1 & \\
\hline Current age (years) & $10(8-15)$ & $8(8-9)$ & 0.788 \\
\hline Age at diagnosis (years) & $5(1-13)$ & $6(2-7)$ & 0.716 \\
\hline Bone age (years) & $11(7-16)$ & $9(8-11)$ & 0.821 \\
\hline Height (cm) & $1.4(1.2-1.7)$ & $1.3(1.2-1.5)$ & 0.334 \\
\hline Weight (kg) & $38(23.5-75.5)$ & $38(22.5-47)$ & 0.593 \\
\hline Radiotherapy & $2(50 \%)$ & $2(50 \%)$ & 0.030 \\
\hline \multicolumn{4}{|l|}{ Risk } \\
\hline Usual & 13 & 2 & 0.651 \\
\hline Moderate & 1 & - & - \\
\hline High & 7 & 2 & 0.522 \\
\hline Relapse to gonads (males) & $0 / 7$ & $1 / 3$ & 0.30 \\
\hline Relapse to central nervous system & 3 & 2 & 0.429 \\
\hline \multicolumn{4}{|l|}{ Tanner } \\
\hline । & 5 & - & \multirow[t]{5}{*}{0.747} \\
\hline II & 8 & 2 & \\
\hline III & 5 & 1 & \\
\hline IV & 2 & 1 & \\
\hline V & 1 & - & \\
\hline \multicolumn{4}{|l|}{ Pelvic ultrasound } \\
\hline Normal & 4 & - & \multirow[t]{2}{*}{0.157} \\
\hline Abnormal & 10 & 1 & \\
\hline Luteinizing hormone (mg/dL) & $1.49(0.06-8.16)$ & $0.88(0.2-2.99)$ & 0.796 \\
\hline
\end{tabular}

normal pubertal development and of $1,62 \mathrm{mg} / \mathrm{dL}$ $(0.15-104 \mathrm{mg} / \mathrm{dL})(p=0.557)$ in those patients with abnormal pubertal development.

\section{Discussion}

In our study, we reported puberty abnormalities in four patients $(16 \%)$, which is similar to the rate reported by Leung et al. ${ }^{7}$, since the group, the diagnosis and the treatment are homogeneous to those in our patients. We found a higher frequency of pubertal abnormalities in males (75\%): one had puberty delay secondary to relapse to the gonads, and the other two had precocious puberty. Of the 15 females, only one had precocious puberty.
History of radiotherapy as part of the treatment is a risk factor for the development of pubertal anomalies. This is consistent with previously published observations in other articles 8,9 .

With regard to the age at diagnosis, the onset of the condition is not a risk factor for the development of pubertal alterations and this is consistent with observations published in the literature ${ }^{10}$.

Although we consider this outcome to be relevant, follow-up in a larger number of patients is necessary to improve our study.

We assume there is a puberty alteration based on clinical examination and imaging studies. We consider it would be convenient to conduct hormonal function dynamic tests in the future in order to improve the diagnostic method. 
Although in the majority of patients gonadal function appears to be preserved, we consider it to be necessary keeping it under surveillance and, if possible, assess the reproductive function.

\section{References}

1. De Fine Licht S, Winther JF, Gudmundsdottir T, et al.; ALiCCS study group. Hospital contacts for endocrine disorders in Adult Life after Childhood Cancer in Scandinavia (ALiCCS): a population-based cohort study. Lancet. 2014;383:1981-9.

2. Van Den Berg H, Van Der Lelie J. Acute lymphoblastic leukaemia in puberty and adolescence. Ann Oncol. 2000;11:1375-9.

3. Landier W, Armenian S, Bhatia S. Late effects of childhood cancer and its treatment. Pediatr Clin North Am. 2015;62:275-300.
4. Howard SC, Pui $\mathrm{CH}$. Endocrine complications in pediatric patients with acute lymphoblastic leukemia. Blood Rev. 2002;16:225-43.

5. Ibáñez IM, Cruz-Martínez O, Parareda A, et al. Evaluación de la pubertad y la función gonadal en pacientes pediátricos supervivientes de un cáncer infantil. An Pediatr (Barc). 2007;66:331-9.

6. Alves $\mathrm{CHB}$, Kuperman H, Dichtchekenian V, et al. Growth and puberty after treatment for acute lymphoblastic leukemia. Rev Hosp Clin Fac Med S Paulo. 2004;59:67-70.

7. Leung W, Hudson M, Zhu Y, et al. Late effects in survivors of infant leukemia. Leukemia. 2000;14:1185-90.

8. Labarta JI, De Arriba A, Sanz de Miguel P, et al. Secuelas endocrinológicas del tratamiento del cáncer en la infancia. Rev Esp Endocrinol Pediatr. 2011;(2).

9. Castro-Feijóo L, Pombo M. Pubertad precoz. An Pediatr Contin. 2006; 4:79-87.

10. Pasqualini T, Rey R, Gottlieb S, et al. Secuelas endocrinológicas del tratamiento de las enfermedades oncológicas en la infancia y adolescencia. RAEM. 2009;46:24-38. 